Saint Louis University School of Law

Scholarship Commons

All Faculty Scholarship

2012

Regulators as Market-Makers: Accountable Care Organizations and Competition Policy

Thomas L. Greaney

Follow this and additional works at: https://scholarship.law.slu.edu/faculty

Part of the Health Information Technology Commons, and the Health Law and Policy Commons 


\section{Regulators as Market-Makers: Accountable Care Organizations and Competition Policy}

\section{Thomas L. Greaney*}

Of the many elements animating structural change under health reform, Accountable Care Organizations (ACOs) have drawn the greatest attention. Supported by scholarship from health policy experts and positioned as the Affordable Care Act's centerpiece for systemic reform, the concept came to represent a potential cure-all for the disorders plaguing American health care. While the program, entitled the Medicare Shared Savings Program (MSSP), focuses on Medicare payment policy, its objectives extend much farther. The ACO strategy entails regulatory interventions that at once aim to reshape the health care delivery system, improve outcomes, promote adoption of evidence based medicine and supportive technology, and create a platform for controlling costs under payment system reform.

Ambitious aims to be sure. Implementation, however, has proved a wrenching process. Because the law entails seismic change requiring norm-shifting, institution building, and law reform, interest groups did not remain quiescent. Moreover, the ACO strategy calls upon disparate governmental entities to cooperate (and in many cases, cede regulatory turf) and asks the private sector to respond responsibly to changes that are rife with possibilities for opportunistic behavior. The regulatory undertaking itself is far reaching--perhaps unprecedented--in its goal of "nation building": fostering institutions that will counter market failure and shift embedded incentives and practices in medicine. Given the abject state of health care markets, a central question is whether implementing regulations and legal standards are adequate to achieve the hoped-for rationalization of health care delivery and financing.

This article looks at the intersection of markets and regulation under the Affordable Care Act. Specifically, it analyzes regulatory interventions under the MSSP designed to foster commercial market competition. Assessing prospects for success, it advances several interrelated arguments. First, in fulfilling the regulatory task of implementing the MSSP, regulators needed to be vigilant to protect against the potential that ACOs may have adverse on private markets. It finds that because the Centers for Medicare and Medicaid Services (CMS) was overly preoccupied with Medicare program issues and hyper-sensitive to criticism from powerful hospitals, the agency missed an important opportunity in its implementing regulations to prevent exacerbation of provider market power. Because existing legal regimes, especially antitrust law, are severely constrained in their ability to deal with extant provider market power, regulation of ACOs requires a cross-platform regulatory approach that addresses market issues.

\footnotetext{
${ }^{*}$ Chester A. Myers Professor of Law and Director, Center for Health Law Studies, Saint Louis University School of Law. Thanks to the Professor Abbe Gluck and the Columbia Law School Health Law \& Society Colloquium and to research assistant James Kovacs.
} 
I. ACOs: Theory and Implementation

The MSSP is one of several initiatives contained in the Affordable Care Act designed to implement "value-based purchasing," a reform strategy that "links payment more directly to the quality of care provided [and] is a strategy that can help to transform the current payment system by rewarding providers for delivering high quality, efficient clinical care." ${ }^{11}$ Section 3022 of the ACA requires the Secretary of Health and Human Services to establish the MSSP to encourage development of ACOs in Medicare. ${ }^{2}$ Although unmistakably designed to foster change in coordinating patient care for Medicare beneficiaries, the ACO strategy has broader goals. Donald Berwick, former Director of CMS, often repeated the "triple aim" of the MSSP: (1) better care for individuals; (2) better health for populations; and (3) slower growth in costs through improvements in care. ${ }^{3}$ The concept of promoting organizations capable of being accountable for the quality and cost of the care they deliver, carries the endorsement of MedPAC ${ }^{4}$ and a number of academic and policy experts, ${ }^{5}$ but is not entirely novel. In many respects, the ACO is the latest in a long line of efforts to develop integrated delivery systems that bear financial responsibility for treatment decisions. ${ }^{6}$ Distinguishing the MSSP from other market-oriented strategies however is the program's objective of leveraging Medicare policy to transform health delivery and payment practices in the private sector. This link is the source of the program's considerable promise and its most vexing regulatory challenges.

The basic design of the MSSP enables provider organizations to share a percentage of the savings they achieve in delivering services to Medicare beneficiaries provided they

\footnotetext{
${ }^{1}$ CMS Hospital Pay-For-Performance Workgroup et al., DeP'T. OF Health and Human

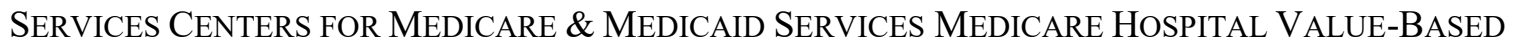
PURCHASING PLAN 1 (2007), available at https://www.cms.gov/AcuteInpatientPPS/downloads/hospital_VBP_plan_issues_paper.pdf.
}

2 Patient Protection and Affordable Care Act, Pub. L. No. 11 $\overline{1}-148,124 \overline{\text { Stat }} 119,395$ (to be codified in scattered sections of 42 U.S.C.) [hereinafter $A C A$ ].

${ }^{3}$ Donald M. Berwick, Launching Accountable Care Organizations-The Proposed Rule for the Medicare Shared Savings Program, 364 NEw ENG. J. MED. e32, e32 (2011).

${ }^{4}$ MEDICARE PAYMENT AdVISORY COMMISSION, IMPROVING INCENTIVES IN THE MEDICARE PROGRAM 40-58 (2009), available at http://www.medpac.gov/documents/Jun09_EntireReport.pdf (MedPAC is an independent Congressional Agency that advises Congress on issues affecting Medicare) [hereinafter MedPAC Report].

5 Elliott S. Fisher et al., Fostering Accountable Health Care: Moving Forward In Medicare, 28 HEALTH AFF. w219, w220-22 (2009), http://tdi.dartmouth.edu/documents/publications/HA\%20Fisher-

McClellan\%20art.pdf; Mark McClellan et al., A National Strategy To Put Accountable Care Into Practice, 29 HEALTH AFF. 982, 985-87 (2010), available at http://content.healthaffairs.org/content/29/5/982.full.html; Stephen M. Shortell \& Lawrence P. Casalino, Health Care Reform Requires Accountable Care Systems, 300 JAMA 95, 96-97 (2008); Stephen M. Shortell et al., How The Center For Medicare And Medicaid Innovation Should Test Accountable Care Organizations, 29 HEALTH AFF. 1293, 1294 (2010), available at http://content.healthaffairs.org/content/29/7/1293.full.html.

6 Policies encouraging integrated delivery of health services through managed care can be traced back to the work of Dr. Paul Elwood and others in the 1960s, which culminated in the passage of the Health Maintenance Act in 1973. 42 U.S.C. § 280(c) (1973) (requiring employers offering health insurance to offer an HMO option). See Robert I. Field, HEAlth CARE REGULATION IN AMERICA: COMPLEXITY, CONFRONTATION, AND COMPROMISE 80-83 (2007). 
meet quality performance standards. To do so, ACOs will need to integrate delivery of services so as to improve the coordination of care reimbursed under Medicare's fee-for-service methodology, invest in infrastructure, and redesign care processes that promote high quality, efficient service and higher value care. ${ }^{7}$ At bottom, the ACO model attempts to solve what Devers and Berenson call a "chicken and egg" problem underlying efforts to address health care costs. ${ }^{8}$ By one account, the core problem in the health care system lies with payment policies that reward volume rather than value; hence reform of provider payment should be the first order of business. Others observe that it is impossible to change the payment system unless delivery system reform first produces organizations capable of handling an altered payment system. The MSSP attempts to tackle this policy quandary by addressing both problems simultaneously, offering financial rewards to providers that organize and reorient their practices to deliver seamless, high quality care.

Looked at from a market perspective, ACOs can be seen as an attempt to mitigate market and regulatory failures that pervade the financing and delivery of health care services. Market imperfections including imperfect agency, information distortions and asymmetry, moral hazard and monopoly are widely recognized shortcomings that undermine consumer welfare in most commercial markets for health care products and services. ${ }^{9}$ The collateral effects of these conditions can be observed in the remarkably fragmented structure of provider markets. With physicians practicing primarily in solo practices or small groups ${ }^{10}$ and group practices often not coordinating across specialty lines or with inpatient facilities, care delivery is extraordinarily uncoordinated and episodic. ${ }^{11}$ Besides causing documented deficiencies in quality, fragmented markets have also worked to impair effective bargaining and comparative shopping. ${ }^{12}$ For example, the absence of vertical integration frustrates the capacity of managed care to negotiate for cost-effective bundles of services. In hospital markets, most patients delegate choice to their

\footnotetext{
7 Medicare Shared Savings Program: Accountable Care Organizations, 76 Fed. Reg. 67,802, 67,806-961 (Nov. 2, 2011) (to be codified at 42 U.S.C. § 1395) [hereinafter Final Rule].

${ }^{8}$ Kelly Devers \& Robert Berenson, Can Accountable Care Organizations Improve the Value of Health Care by Solving the Cost and Quality Quandaries?, URBAN INSTITUTE (Oct. 2009), available at http://www.urban.org/uploadedpdf/411975_acountable_care_orgs.pdf.

${ }^{9}$ Kenneth J. Arrow, Uncertainty and the Welfare Economics of Medical Care, 53 AM. EcON. REV. 941, 947 (1963) ("The failure of one or more of the competitive preconditions has as its most immediate and obvious consequence a reduction in welfare below that obtainable from existing resources and technology, in the sense of a failure to reach an optimal state in the sense of Pareto."). See generally David Dranove \& Mark A. Satterthwaite, The Industrial Organization of Health Care Markets, in 1B HANDBOOK OF HEALTH ECONOMICS 1093, 1095 (Anthony J. Culyer \& Joseph P. Newhouse eds., 2000) (describing market imperfections in health care); Thomas L. Greaney, The Affordable Care Act and Competition Policy: Antidote or Placebo? 89 OR. L. REV. 810, 817 (2011).

${ }_{10}$ Allison Liebhaber \& Joy M. Grossman, Physicians Moving to Mid-Sized Single Specialty Practices, QUALITY \& CARE DELIVERY TRACKING REPORT, Aug. 2007, at 1-2, available at http://www.hschange.com/content/941/941.pdf.

11 See generally The Fragmentation of U.S. HeAlth CARE: CAUSES AND SOlutions (Einer R. Elhauge, ed., 2010) [hereinafter Fragmentation of U.S. Health Care].

${ }^{12}$ See Thomas L. Greaney, Competition Policy and Organizational Fragmentation in Health Care, 71 U. PITT. L. REV. 217, 229 (2009). See also Einer Elhauge, Why We Should Care About Health Care Fragmentation and How to Fix It, in THE Fragmentation OF U.S. HeAlTH CARE, 1 (Einer R. Elhauge, ed., 2010).
} 
physicians who do not internalize the hospitals' costs of technology or excess capacity. In this context, hospitals benefit more by competing for physician affiliation though various forms of nonprice competition than by economizing for the benefit of efficient contracting. Regulation and government payment policies, which strongly influence the practices and norms in the private sector, also bear significant responsibility for market inefficiencies in health care. Most notably, the longstanding reliance on fee-for-service methods of payment has spawned an ethos of provider payment that rewards volume and disincentivizes cost-benefit tradeoffs. ${ }^{13}$

\section{ACOs under the MSSP Program}

While the ACO strategy relies on flexibility in design and structure to accommodate local market conditions, the core concept envisions a local entity and a related set of providers, including primary care physicians, specialists, and hospitals that can be held accountable for the cost and quality of the entire continuum of care delivered to a defined population such as Medicare beneficiaries or subscribers to private insurance plans. ${ }^{14}$ Payments to those entities can take the form of population-based reimbursements such as capitation, fee for service payments subject to agreed-upon shared savings when the ACOs costs fall below pre-established benchmarks, or other arrangements. Notably, the MSSP program adopts a "shared savings" approach under which participating ACOs share in cost reductions achieved compared to benchmark levels (what Medicare would have paid under fee for service payment for the ACOs beneficiaries). ACO providers will continue to be paid under Medicare's fee-for-service methodologies but subject to a bonus structure designed to encourage economizing the total costs for their cohort of beneficiaries. Thus, ACOs constitute an intermediary model for reform that does not require providers to assume insurance and technical risk for care provided to beneficiaries but still provides financial incentives to reorient delivery arrangements. ${ }^{15}$ As such the bonus-based shared savings model may ultimately prove to be a transitional model, one that facilitates the transition to a more complete assumption of financial responsibility. For entities already prepared to accept such obligations, CMS has also established a pilot program for "Pioneer ACOs" that will employ prepaid population-based reimbursement methods such as capitation for selected ACOs that can demonstrate sufficient capabilities to manage this kind of risk. $^{16}$

Although ACOs may involve a variety of structural configurations among providers, such as integrated delivery systems, primary care medical groups, hospital-based systems and virtual

${ }^{13}$ See Uwe E. Reinhardt, Can Efficiency in Health Care Be Left to the Market?, 26 J. HEALth PoL. POL'Y \& L. 967, 987 (2001).

${ }^{14}$ See Shortell \& Casalino, supra note xx at; Elliot S. Fisher et al., Fostering Accountable Health Care: Moving Forward In Medicare, 28 HEALTH AFF. W219, w220 (2009), available at http://content.healthaffairs.org/content/28/2/w219.full.html; MedPAC Report, supra note xx at 39.

15 Robert A. BERENSON \& RACHEL A. BURTON, ACCOUNTABLE CARE ORGANIZATIONS In MEDiCARE AND THE PRIVATE SECTOR: A STATUS UPDATE 8-9 (2011), available at http://www.urban.org/UploadedPDF/412438-Accountable-Care-Organizations-in-Medicare-and-thePrivate-Sector.pdf (stating that the MSSP "puts providers in a position somewhere between being paid solely through volume-increasing fee-for service payments and operating within tightly managed, prospectively defined capitated budgets that place providers at full financial risk for all spending for their enrolled populations.").

16 See Pioneer ACO Model, CTR. FOR MediCARE \& MEDiCAID InNOVATION, http://innovations.cms.gov/initiatives/aco/pioneer/ (last visited date). 
networks of physicians such as independent practice associations, designers of the model stress that all accountable care organizations must have a strong base of primary care. ${ }^{17}$ That emphasis is well placed given the underlying defects in the way health care is delivered. Health economists and policy experts place much of the responsibility for cost and quality deficiencies in health care on the fragmented nature of the American system (more accurately, "non-system"). ${ }^{18}$ With most health professionals working in separate institutional settings with little collaboration, shared information, or common protocols, clinical decisions lack an effective mechanism to assess cost or value. Indeed, fragmentation served to undermine managed care's incentives to promote development of efficient delivery organizations. With physicians typically contracting with multiple payors, incentives to change practice styles or adopt other methods for controlling cost and improving quality by conforming to the protocols of any single payor are attenuated. As a result, fee-for-service payment, the predominant method of reimbursement in public and private insurance, neglects many of the services necessary for cost-effective care delivery. For example, it fails to pay for care coordination and information exchanges, and undervalues other valuable services such as cognitive services and communications outside care encounters. ${ }^{19}$

While ACOs bear a family resemblance to health maintenance organizations in that they offer a network of providers which will have financial incentives to economize on care, there are significant differences. ${ }^{20}$ ACOs are controlled by providers rather than insurers and, unlike HMOs, beneficiaries are assigned to ACOs and do not actively select their plan. Moreover, beneficiaries are permitted to utilize physicians outside the ACO to which they have been assigned. As designed for Medicare beneficiaries under the MSSP, ACOs operate under a different incentive structure than HMOs. ACOs can choose between two payment models. Under Track 1 (the "one-sided" payment model) the ACO will share in savings realized without the risk of sharing in any losses. ${ }^{21}$ More experienced ACOs that are ready to share in losses with greater opportunity for reward may elect the two sided model under Track 2 which provides for higher sharing rates than would be available under the one-sided model, but require sharing losses that may occur. ${ }^{22}$ Finally, the MSSP initiative requires that CMS apply explicit and detailed quality metrics to ACOs and that it closely monitor their performance. ${ }^{23}$

The legislative history of the MSSP is limited. Inclusion of the program in the new law was strongly influenced by the endorsement of the concept in 2009 by MedPAC, ${ }^{24}$ though the ultimate model adopted differs in some important respects. For example, MedPAC proposed mandatory participation of at least one hospital in each ACO while the MSSP contains no such restriction. Although the Act's limited legislative history affords no explanation for this departure, it probably reflects the drafters' perception that hospital participation may undermine

\footnotetext{
${ }_{17}$ Mark McClellan et al., supra note xx at 983 (2010).

18 See generally Fragmentation of U.S. Health Care, supra note xx; Francis J. Crosson, Medicare: The Place To Start Delivery System Reform, 28 HeAlTH AFF. w232, w232 (2009).

19 See Greaney, supra note xx at 227; Einer Elhauge, Why We Should Care About Health Care

Fragmentation, in THE FRAGMENTATION OF U.S. HEALTH CARE, supra note xx .

${ }^{20}$ See Berenson \& Burton, supra note $\mathrm{xx}$ at 2.

${ }^{21}$ Final Rule, supra note $\mathrm{xx}$ at $67,904$.

22 Id

${ }^{23}$ Id. at 67,942 .

${ }^{24}$ See generally MedPAC Report, supra note $\mathrm{xx}$ at 39-58.
} 
ACOs ability to achieve savings by tackling excess hospital expenditures, commonly thought to be the most promising avenue for cost reductions. ${ }^{25}$

Two interconnected objectives underlying the design of the MSSP. Perhaps the most important consideration for the immediate goal reforming Medicare reimbursement is the need to solve the "chicken and egg" dilemma discussed earlier. Congress recognized that it was essential to stimulate formation of organizations that could receive and distribute reimbursement and be responsible for the quality of care under the several new payment arrangements contained in the ACA and developing in the private sector. Thus innovative programs in the ACA providing for bundled payment, ${ }^{26}$ value based purchasing, ${ }^{27}$ and other arrangements presuppose the formation of provider organizations that can assume the responsibilities for care coordination and internal governance and sharing of financial responsibilities. ${ }^{28}$ The second objective concerns spillovers from the MSSP in the private sector. Recognizing that ACOs were more likely to succeed and have transformative effects on the delivery system if they obtained acceptance by commercial insurers and employers, the architects of the MSSP were eager to encourage facilitation of private sector initiatives. ${ }^{29}$

\section{Prospects for Success: Experience and Critiques}

The legislative origins of the Medicare Shared Savings Program can be traced to a law passed in 2000 establishing the Physicians Group Practice Demonstration (PGP) which enabled nine selected integrated physician groups and one physician hospital organization to keep a portion of the savings they generated in serving Medicare, beneficiaries with incentives to increase their share of savings based on a set of 32 quality measures. ${ }^{30}$ Notably this experiment did not provide strong evidence that organizations like ACOs could readily achieve substantial savings despite the fact that the participants were relatively sophisticated medical groups experienced in providing integrated care. Although all of the participants were able to improve the quality of the services they provided, only two participants lowered cost sufficiently to receive shared savings in all five years of the program, and three received no bonus in any year. ${ }^{31}$ Despite the disappointing results, these outcomes may not be predictive of the prospects for ACOs under the MSSP. Incentives to change practice patterns in a short term program would need to be substantial to encourage substantial savings from providers. Moreover, inasmuch as

25 Andrew A. Kasper, Antitrust Review of Accountable Care Organizations: An Assessment of FTC and DOJ's Relaxed Approach to Regulating Physician-Hospital Networks, 90 N.C. L. REV. 203, 214 (2011).

${ }^{26}$ ACA $\$ 3023$.

27 ACA $\S \S 3001,3006,10301,10335$.

${ }_{28}$ See Kasper supra note xx at 214 ("Congress appears to have viewed the ACO program and hospitalphysician bundled payment programs as intimately related, placing the payment-bundling pilot program immediately after the Shared Savings Program in the bill.").

${ }^{29}$ See e.g., Final Rule, supra note $\mathrm{xx}$ at 76 (noting a need to "harmonize" MSSP eligibility rules with requirements of antitrust law applicable to ACOs operating in the private sector).

30 Medicare, Medicaid, and SCHIP Benefits Improvement and Protection Act, Pub. L. No. 106-554, § 114 Stat. 2763, 2763A-509 (2000).

${ }^{31}$ Kathleen K. Sebelius, Report to Congress: Physician Group Practice Demonstration Evaluation Report, 2009,www.cms.gov/reports/downloads/RTC_Sebelius; Gail Wilensky, Lessons from the Physician Group Practice Demonstration - A Sobering Reflection, 365 NEW ENG. J. MED. 1659, 1660 (2011), available at www.nejm.org/doi/full/10.1056/NEJMp1110185. 
fee-for-service payment (both in Medicare and private insurance plans) continued to reward higher volume, it was probably unrealistic to expect providers to radically change their business models in a pilot program. ${ }^{32}$

ACO developers face formidable obstacles in putting the pieces together. For example, integrating and collectivizing medical practices entails redistributing incomes among providers - a process certain to entail substantial frictions. ${ }^{33}$ Because hospital-related wasteful and unnecessary care constitutes the largest avoidable costs in health care, ${ }^{34}$ hospitals should be focus of ACOs' cost-cutting strategy. At the same time, hospitals are most likely to have access to the capital necessary to fund start-up costs for ACOs and historically have been resistant to sharing control with physicians. ${ }^{35}$ Moreover, physicians face practical obstacles to reaching agreement among themselves. There are substantial income disparities among physicians, ${ }^{36}$ with primary care physicians earning far less than specialists who in some cases can reap sizeable profits from the provision of ancillary services. Increased consolidation among specialty physicians ${ }^{37}$ confers substantial bargaining power that will make it difficult to reward primary care practitioners who under many ACO models serve as gatekeepers reducing the amount of unnecessary procedures and tests. As one respected expert on physician-hospital relations put it, ACOs will find single specialty groups "as hard to absorb as gravel in the digestive tract.,"38

Proponents of the ACO strategy argue forcefully that the experiment is the last best hope for a market-driven rationalization of the health care system. Jay Crosson, for example, contends that the ACO concept is "too vitally important to fail," predicting that the likely alternative if ACOs do not take root could be indiscriminate, across-the-board cuts to provider payment rates. ${ }^{39}$ Optimistic observers suggest that ACOs will improve the dynamics of competition ${ }^{40}$ and may

${ }^{32}$ Berenson \& Burton, supra note $\mathrm{xx}$.

33 Jeff Goldsmith, Accountable Care Organizations: The Case for Flexible Partnerships Between Health Plans and Providers, 30 HEALTH AFF. 32, 35 (2011) (noting problems with income allocation among physician networks "doomed many provider-organizations in the past").

34 Id.

${ }^{35} I d$. at 33 ("[F]or many hospital administrators, alignment is a code word for "physicians work for me and will do what I say."').

${ }^{36}$ See Ya-Chen Tina Shih \& Thomas R. Konrad, Factors Associated with the Income Distribution of Full-Time Physicians: A Quantile Regression Approach, 42 HEALTH SERV. RES. 1895, 1906-09 (2007).

${ }^{37}$ Hearing on Health Care Industry Consolidation Before the Subcomm. on Health of the H. Comm. on Ways and Means 112th Cong. (2011) (statement of Martin Gaynor, Professor, Carnegie Mellon University) (noting the absence of nationwide data but observing concentration in physician specialty markets). See also Lawton Burns \& Mark V. Pauly, Integrated Delivery Networks: A Detour on the Road to Integrated Health?, 21 HEALTH AFF. 128 (2002).

${ }^{38}$ Goldsmith, supra note $\mathrm{xx}$ at 35.

39 F. Jay Crosson, The Accountable Care Organization: Whatever Its Growing Pains, the Concept Is Too Vitally Important to Fail, 30 HeALTH AFF. 1250, 1254 (2011).

${ }^{40}$ Ezekiel J. Emanuel \& Jeffrey B. Liebman, The End of Health Insurance Companies, N.Y Times OPINION PAGES (Jan. 30, 2012, time), http://opinionator.blogs.nytimes.com/2012/01/30/the-end-of-health-insurancecompanies/ (stating that ACOs offer "a better form of competition" because consumers are better able to choose physicians than deal with "a bewildering array of copayments, deductibles and annual out of pocket maximums" in selecting a health plan). See also Shortell et al., supra note xx. 
ultimately displace private insurance altogether. ${ }^{41}$ Other prominent health policy experts are less sanguine about the compatibility of ACOs and a competition-driven marketplace, offering scenarios in which the failure of competition to restrain cost increases driven by dominant providers ultimately leads to rate regulation, ${ }^{42}$ or simply fail to achieve critical mass because of the intransigence of entrenched providers. ${ }^{43}$

\section{The ACO Regulation}

On March 31, 2011, CMS released its proposed regulation for the MSSP. ${ }^{44}$ In addition, and as part of the inter-agency collaborative administrative process, other ACO-related guidelines were issued: CMS and HHS Office of Inspector General (OIG) jointly issued a notice outlining proposals for waivers of certain Federal laws - the physician self-referral law, the antikickback statute, and certain provisions of the civil monetary penalty law - in connection with the Shared Savings. ${ }^{45}$ The Federal Trade Commission and the Department of Justice jointly issued a "Proposed Statement of Enforcement Policy Regarding Accountable Care Organizations Participating in the Medicare Shared Savings Program" (Antitrust Policy Statement), which announced safe harbors for less inclusive provider collaborations and a mandatory review process for larger ones. ${ }^{46}$ The Internal Revenue Service (IRS) issued a notice requesting comments regarding the need for guidance on participation by tax-exempt organizations in the Shared Savings Program through ACOs. ${ }^{47}$ Responding in part to the unfavorable response to the proposed rule, ${ }^{48}$ the Center for Medicare and Medicaid Innovation (CMMI) added two additional programs before the comment period for the rule had closed. It announced the Pioneer ACO Program $^{49}$ which is designed for health care organizations and providers that experienced in coordinating care for patients across care settings, proposes terms that allow such provider

${ }^{41}$ Emanuel \& Liebman, supra note xx at (predicting that "by 2010, the American health insurance will be extinct" as ACOs will replace private health insurance companies).

${ }^{42}$ See e.g., Hearing on Health Care Industry Consolidation Before the Subcomm. on Health of the H. Comm. on Ways and Means 112th Cong. (2011) [hereinafter Ginsburg Testimony] (statement of Paul B. Ginsburg, President, Center for Studying Health System Change) (documenting increasing provider market power and concluding that ineffective market competition may lead to government rate review or rate setting); Clark C. Havighurst \& Barak Richman, The Provider Monopoly Problem in Health Care, 89 OR. L. REV. 847, 874 (2011) (citing rate regulation as possible remedy to hospital market dominance).

${ }^{43}$ Goldsmith, supra note $\mathrm{xx}$ at 35.

${ }^{44}$ Medicare Shared Savings Program: Accountable Care Organizations, 76 Fed. Reg. 19,528, 19,528 (Apr. 7, 2011) [hereinafter Proposed Rule] (to be codified in 42 U.S.C. § 1395).

45 Waiver Designs in Connection With the Medicare Shared Savings Program and the Innovation Center, 76 Fed. Reg. 19,655, (Apr. 7, 2011) (to be codified in scattered sections of 42 U.S.C.).

46 Proposed Statement of Antitrust Enforcement Policy Regarding Accountable Care Organizations Participating in the Medicare Shared Savings Program, 76 Fed. Reg. 21,894, (Apr. 19, 2011) [hereinafter Proposed Antitrust Policy Statement].

${ }^{47}$ I.R.S. Notice 2011-20, available at http://www.irs.gov/pub/irs-drop/n-11-20.pdf. [hereinafter IRS Notice].

48 See infra notes $\mathrm{xx}$ and accompanying text.

49 See supra note $\mathrm{xx}$. The program announcement and application form may be found at http://innovations.cms.gov/areas-of-focus/seamless-and-coordinated-care-models/pioneer-aco. 
groups to move more rapidly from a shared savings payment model to a population-based payment model "on a track consistent with, but separate from, the Medicare Shared Savings Program." ${ }^{\circ 0}$ In addition, CMS established an Advance Payment Model for ACOs, which were designed to broaden the opportunity for smaller health care provider groups (specifically those that do not include inpatient facilities other than critical access hospitals) to participate in the MSSP by providing upfront payments to be recouped from future shared savings the ACOs earn. $^{51}$

The proposed rule generated over 1300 comments many of which were highly critical. Provider groups were especially concerned with the extensive quality requirements CMS proposed to review ACO performance (65 separate measures); the imposition of "two sided risk" in the third year of operation; identification of assigned beneficiaries for whom the ACO would be held accountable for at the end of the year, after care had been delivered, instead of the beginning; the requirement that at least 50 percent of an ACO's primary care physicians be meaningful users of electronic health records. ${ }^{52}$ Although criticisms came from many quarters including some who argued the regulations were too lax or insufficiently supportive of rural and safety net interests, provider interest groups were the most vocal and pointed in their comments. The health industry trade press and policy experts echoed providers' critique, concluding that the burdensome and inapt regulatory structure proposed by CMS would doom the ACO initiative. ${ }^{53}$ To the surprise of some, ${ }^{54} \mathrm{CMS}$ made some significant changes in its Final Rule in response to concerns expressed by commenters. In addition, the FTC and Department of Justice, the Office of Inspector General and the Internal Revenue Service each amended their proposed policies in significant ways. Together these changes seemed to mollify critics and prompted predictions that ACO program was "back on track." 55

\footnotetext{
${ }^{50}$ Center for Medicare and Medicaid Innovation, Pioneer ACO Model available at http://innovations.cms.gov/areas-of-focus/seamless-and-coordinated-care-models/pioneer-aco/.

${ }^{51}$ Center for Medicare and Medicaid Innovation, Advance Payment Model, available at http://innovations.cms.gov/areas-of-focus/seamless-and-coordinated-care-models/advance-payment/.

52 See Berenson \& Burton supra note $\mathrm{xx}$ at 1.

${ }^{53}$ Press reports ranged from critical to apoplectic. See e.g., Avik Roy, How Obamacare is Destroying Accountable Care Organizations, FORBES (Aug. 19, 2011), http://www.forbes.com/sites/aroy/2011/08/19/how-obamacare-is-destroying-accountable-careorganizations/.

54 See Phil Galewitz \& Jenny Gold, HHS Releases Final Regulations For ACOs, KAISER HeALTH News (Oct. 20, 2011), http://www.kaiserhealthnews.org/stories/2011/october/20/accountable-care-organizationrules-regulations.aspx.

55 N.C. Aizenman, Obama Administration Revises Medicare Rules For Coordinated Care, WASH. PosT (Oct. 20, 2011), http://www.washingtonpost.com/national/health-science/obama-administration-revisesmedicare-rules-for-coordinated-care/2011/10/20/gIQAsT7W1L_story.html (stating new rule "greeted with jubilation by groups representing doctors and hospitals"); Noam M. Levy, Changes seek to save key aspect of healthcare law, L.A. TIMES (Oct. 20, 2011), http://articles.latimes.com/2011/oct/20/nation/lana-medicare-partnerships-20111021.
} 
The Final Rule modifies the Proposed Rule in a number of important respects. While by no means exhaustive, the following changes are particularly germane to the market issues discussed in this paper.

Reduced quality and structural requirements. The Final Rule reduced requirements for "meaningful use" of electronic health records, lowered the number of performance measures for bonus eligibility was reduced from 65 to 33 and eased other quality reporting requirements. ${ }^{56}$ In addition, ACOs will now be allowed to add or subtract providers within the performance period.

Antitrust Review. The Final Rule withdraws a requirement that ACOs with dominant provider participants obtain prior antitrust clearance from the FTC or Department of Justice as a condition of approval for participation in the MSSP. ${ }^{57}$

Beneficiary assignment. Rather than assign beneficiaries retrospectively to ACOs, the Final Rule adopts a "step-wise" approach that will provide ACOs will a timely list with quarterly updates of the beneficiaries that are likely to be attributed, enabling ACOs to reach out to beneficiaries, while reconciling the list at the end of the year so that the ACO is not held responsible for those beneficiaries who shifted their care to other providers during the year. ${ }^{58}$

Governance. The Final Rule relaxed requirements that participants (providers and suppliers) have proportionate control over the organizations. The IRS has indicated that it will relieve tax exempt ACOs from the requirement that exempt participants such as hospitals have "control" over the ACO ${ }^{59}$ While preserving a requirement that 75 percent of ACO's governing body be chosen by ACO participants (providers and suppliers), the Final Rule allows for alternative structures that "involve ACO participants in innovative ways in ACO governance."

Financial rewards. The Final Rule revised the formula for distributing savings so that ACOs achieving savings will receive a share of the first dollar of savings rather than have to first exceed a benchmark.

Waivers of Fraud and Abuse Laws. Pursuant to statutory authority contained in the ACA, HHS set out a number of waivers from the Physician Self-Referral Law, the federal antikickback statute, and the gainsharing Civil Monetary Penalty law. ${ }^{60}$ These waivers will allow providers to share startup costs, distribute shared savings, and provide certain incentives to beneficiaries without running afoul of those laws.

\footnotetext{
${ }^{56}$ Final Rule, supra note xx at 67,891.

${ }^{57}$ Id. at 67,843. See also Statement of Antitrust Enforcement Policy Regarding Accountable Care Organizations Participating in the Medicare Shared Savings Program, 76 Fed. Reg. 67,026 (Oct. 28, 2011) [hereinafter Final Policy Statement]. See discussion infra note xx and accompanying text.

${ }^{58}$ Final Rule, supra note $\mathrm{xx}$ at $67,891$.

59 I.R.S. Notice 2011-20, available at http://www.irs.gov/pub/irs-drop/n-11-20.pdf; I.R.S. Fact Sheet FS 2011-11, available at http://www.irs.gov/pub/irs-news/fs-2011-11.pdf. http://www.irs.gov/newsroom/article/0, id=248490,00.html.

60 Waiver Designs in Connection With the Medicare Shared Savings Program and the Innovation Center, 76 Fed. Reg. 19,655, 19,655-19,660 (Apr. 7, 2011).
} 
Shared savings without sharing risk. Backing away from a proposed requirement that all ACOs bear risk by year three, the Final rule allows ACOs to choose a three-year, shared-savingsonly version. ${ }^{61}$

These changes illustrate myriad, and sometimes conflicting, policies embedded in the ACO experiment. For example, a central objective of the MSSP is to stimulate investment in ACOs. However this entails nuanced regulation that simultaneously encourages ACO formation by as-yet unintegrated providers while also rewarding entities already operating as integrated delivery systems. In addition, ACOs hold the promise of restraining cost growth in the Medicare program but at the same time encouraging investments in evidence-based medicine, "patientcentered" delivery, electronic health records and other service innovations. Further, a key determinant of the MSSP's success will be its coordination and influence in commercial insurance and delivery markets. As will be discussed in the following sections of this article, this goal calls for flexibility in regulatory matters and careful attention to avoid legal standards that invite cost shifting or other harmful spillovers in those markets.

\section{Regulating Medicare to Improve Private Markets}

Since its inception, traditional Medicare has reimbursed providers using methodologies that reward volume. Medicare Part B pays physicians on a fee-for-service basis, i.e. issuing a separate payment for each service provided to Medicare beneficiaries. ${ }^{62}$ Hospitals, reimbursed under Part A, receive prospective reimbursements for all services provided to beneficiaries under specific diagnoses. Although this methodology is commendable for bundling hospital services and thus mitigating volume-enhancing incentives to some extent, it not free of cost-escalating incentives. For example, historically hospitals have been overpaid for readmitted patients and, under some circumstances, for patients with multiple diagnoses. ${ }^{63}$ Moreover, physician and hospital incentives are misaligned. As a result of fee-for-service payment physicians have strong incentives to increase the volume of services provided in hospitals, while prospective payment rewards hospitals for economizing on care. With independent physicians calling the shots on care in most hospitals, their power to admit, prescribe tests and services, and extend the stays of patients in hospitals have caused hospital costs to escalate enormously despite prospective payment reforms. Hospitals have responded by increasing admissions and have benefited by generous reimbursement for diagnoses served by new technologies. ${ }^{64}$ Further, while Congress

\footnotetext{
${ }^{61}$ Final Rule, supra note $\mathrm{xx}$ at $67,929$.

${ }^{62}$ See Alice G. Gosfield, Value Purchasing In Medicare Law: Precursor to Health Reform, 20 AM. J.L. \& MED. 169, 174 (1994).

${ }^{63}$ Almost $18 \%$ of hospitalizations result in readmissions within thirty days, costing the Medicare program $\$ 15$ billion in 2005. MEDICARE PAYMENT ADVISORY COMMISSION, PROMOTING GREATER EFFICIENCY IN MEDICARE (2007), available at http://www.medpac.gov/documents/Jun07_EntireReport.pdf.

${ }^{64}$ MedPAC, Annual Report at xx.
} 
has repeatedly attempted to control Medicare costs through per service rate controls, expansion in the amount of services per patient have more than offset price regulation.

As described above, the MSSP seeks to encourage formation of integrated delivery systems capable of receiving value based payments. Although the ACA gave the Secretary of HHS discretion to employ capitated payment models for ACOs, ${ }^{65}$ she chose not do so. Instead, the MSSP continues fee for service payment and provides bonuses to ACOs if their patients' total health care costs are below a projected amount based on the historic spending of providers in that ACO. The program's financial incentives are skewed to minimizing the transitional uncertainties in other ways as well. For example it rewards cost savings regardless of whether the benchmark of the particular ACO is relatively high or low and ACOs may seek a "bonus only" model and avoid risking financial losses in its initial three year contract.

Despite the market-improving potential of ACO delivery systems, the private market has not led the way. While a number of commercial insurance companies have initiated programs to reward ACO delivery models most of them rely on a shared savings model rather than requiring ACOs to share financial risk. ${ }^{66}$ Historically, Medicare payment policies strongly influence private payment with private payors generally adopting the methods and details of government payment. They do so as a result of collective action problems - the difficulties inherent in securing providers' acceptance of innovative payment methodologies often requiring new practice methods for only a fraction of their patient base.

The architects of health reform were especially attuned to the goal of encouraging widespread adoption of the ACOs and therefore strove to design the MSSP to encourage ACOs serving Medicare beneficiaries to contract with private payers as well. ${ }^{67}$ This required CMS to strike a delicate balance between serving Medicare's programmatic goals while also innovative and competitive ACO formation in the private sector. As discussed below the private and public payment sector share common interests in promoting development of efficient delivery systems and preventing harms to patients. At the same time the regulatory mission of CMS is centered on advancing the goals of the Medicare program and not on supervising the market served by private insurance.

\footnotetext{
${ }^{65}$ ACA $\$ 3022$.

${ }^{66}$ As of the end of 2011, at least eight private insurers have ACO contracts employing a shared risk payment model (making providers eligible for both bonuses and penalties) and 27 have shared savings programs (paying bonuses only). None in the private sector have moved to full capitation. Berenson \& Burton, supra note $\mathrm{xx}$ at 3.

${ }^{67}$ For example, the Affordable Care Act provides that CMS should give preference to ACO applicants that have contracts with private insurers. ACA $\S 1324$. Other inducements aimed at encouraging private sector ACOs include relaxation and clarification of antitrust standards. See infra note xx; Final Rule, supra note $\mathrm{xx}$ at 67,834 (noting advance payment of MSSP bonuses to enable small provider groups to absorb startup costs).
} 
In many respects the goals of the Medicare program and private insurance payers are congruent. Encouraging providers to develop more efficient delivery organizations has the potential to improve quality and outcomes. Studies show that integrated delivery systems and multi-specialty provide more preventive services ${ }^{68}$ and have on average better quality indicators. ${ }^{69}$ In addition, integrated systems are a pre-requisite for channeling and distributing payments to providers so as to permit effective rationalization of care. Providers accepting responsibility for care delivery for a defined population will of necessity need to coordinate delivery and agree on protocols for practice, distribution of income and a variety of other issues. Numerous other reforms contained in the ACA such as bundled payment pilot programs ${ }^{70}$ also depend on providers adopting integrative delivery models.

This congruence notwithstanding, given CMS's regulatory mission and the fiscal and political climate in which it operates today, it is at least questionable whether the MSSP will adequately serve the interests of the private market. Most significant is the fact that Medicare relies primarily administrative pricing and command regulation to control costs. That is, CMS is unlikely to focus on promoting provider competition - the driving force for cost control in private insurance markets - because, to put it bluntly, Medicare can dictate its prices to doctors and hospitals. ${ }^{71}$ Operating in a political environment in which government expenditures are under intense scrutiny, the impulse to shift costs to the private sector is likely to be significant. Moreover, concerns about the excesses of managed care that surfaced in the 1990s have not disappeared, ${ }^{72}$ and government regulators may be overly zealous in promulgating regulations designed to protect consumers. For example, it appears that CMS overlearned the lessons of the managed care backlash in fashioning excessively restrictive regulations for ACOs in its Proposed

\footnotetext{
${ }^{68}$ Shortell et al., supra note $\mathrm{xx}$ at 96.

69 The Demonstration project that preceded the ACA provides some evidence that integrated delivery under ACO-type incentives will improve quality of care. The 10 physician organizations in that demonstration program met performance benchmarks for the vast majority of the applicable quality measures (32 measures covering diabetes, coronary artery disease, congestive heart failure, hypertension, and cancer screening). Berenson and Burton, supra note $\mathrm{xx}$ at 7.

70 ACA $\S 3023$. See generally Peter S. Hussey et al., The PROMETHEUS Bundled Payment Experiment: Slow Start Shows Problems in Implementing New Payment Models, 30 HeALth AFF. 2116, 2117 (2011).

${ }^{71}$ Professors Havighurst and Richman express doubt that CMS would be attentive to private market competition:

One might wonder, of course, whether a governmental single payer like Medicare would ever have the mission, the impulse, or the requisite creativity to be helpful in making private markets for health services effectively competitive. The more likely scenario, unfortunately, is that Medicare will be happy to see costs shifted to the private sector--and may even reward ACOs' cost shifting as cost savings.

Clark C. Havighurst \& Barak Richman, The Provider Monopoly Problem in Health Care, 89 OR. L. REV. 847, 874 (2011).

72 See Thomas L. Greaney, Regulating to Promote Competition in Designing Health Insurance Exchanges, 20 U. Kan. J. L. \& Pub. Pol'y 237 (2011)(noting the somewhat misplaced emphasis in the debate over health reform on the excesses of managed care).
} 
Rule, ${ }^{73}$ although it subsequently responded to strenuous criticisms by reducing the quality measures for which organizations will be accountable in its Final Rule. ${ }^{74}$

A central problem confronting governmental efforts to regulate ACOs with an eye to protecting competition in private markets is the issue of cost shifting. Some question whether Medicare payment policies have in the past caused providers to shift costs to private payers. Economic theory challenges the simplest cost-shifting formulation-- that providers raise their prices to private payers to recoup whatever they may lose because Medicare pays less-because monopoly providers are likely to be charging private payers a profit-maximizing price already. However, cost shifting is entirely possible where providers have unused bargaining leverage. Given that over seventy percent of acute care hospitals are nonprofit, thus arguably operating under somewhat different incentives than for-profit entities, and that political and social factors may affect hospital board's willingness to maximize profits, the existence of unused bargaining power is plausible.

While a number of empirical studies suggest that cost shifting does sometimes occur, ${ }^{75}$ a more nuanced account has emerged from an examination of the relationship between market competition and hospital costs. This analysis relies on the well-documented tendency of hospitals in concentrated local markets to exercise their bargaining leverage to raise prices they charge to private insurers. Although they may extract these profits regardless of whether Medicare payments are adequate or inadequate to cover the treatment costs for Medicare beneficiaries, empirical analysis indicates that hospitals use these revenues to engage in the so-called "medical arms race" (expansions in capacity, acquisition of new clinical technologies, enhancement of staff budgets). ${ }^{76}$ As the 2009 MedPAC annual report explains, this hydraulic explains the fact that dominant hospitals have higher costs per patient, and therefore lower Medicare margins

73 See Scott Gottlieb, Accountable Care Organizations: The end of Innovation in Medicine?, 3 AM. ENTERPRISE INST. FOR PUB. POL. RES. 1, 1 (2011) (citing criticisms of the proposed rule).

${ }^{74}$ Responding to many comments that the measurement targets were overly burdensome, CMS reduced the quality measures from 65 to 33 and reduced the number of "domains" governing quality indicators. To satisfy quality performance requirements for a domain, ACO must report all measures within a domain and score above the minimum attainment level determined by CMS on $70 \%$ of the measures in a domain. Moreover, CMS backed off a requirement that ACOs must meet the quality performance thresholds for all of the proposed measures to be eligible for shared savings, requiring instead that ACOs achieve the minimum attainment level for at least one measure in each of the four domains to be eligible to receive shared savings. See Final Rule, supra note xx at 67,891.

${ }^{75}$ Rexford E. Santerre, The Welfare loss from Hospital Cost-Shifting Behavior: A Partial Equilibrium Analysis, 14 HEALTH ECON. 621, 624 (2005) (concluding that "a 1 percent relative decrease in the average Medicare price is associated with a 0.17 percent increase in the corresponding price paid by privately insured patients."); Vivian Wu, Hospital Cost-Shifting Revisited: New Evidence From The Balanced Budget Act Of 1997, 10 InT J. HEALTH CARE FinANCE ECON. 61, 76 (2010); Jack Zwanziger \& Anil Bamezai, Evidence Of Cost-Shifting In California Hospitals, 25 HEALTH AfF. 197(2006); M.A. Morrisey, Hospital Cost Shifting, A Continuing Debate, ISSUE BRIEF NO. 180 (Employee Benefit Research Institute), available at http://www.ebri.org/pdf/briefspdf/1296ib.pdf.

${ }^{76}$ See James Robinson, Hospitals Respond To Medicare Shortfalls By Both Shifting Costs And Cutting Them, Based On Market Concentration, 30 HeALTH AFF. 1265, 1267 (2011); Jeffrey Stensland et al., Private-Payer Profits Can Induce Negative Medicare Margins, 22 HEAlth AfF. 1045, 1049 (2010). 
because Medicare pays fixed prices that are insensitive to market power of hospitals. ${ }^{77}$ (Conversely, hospitals in competitive markets realize higher Medicare margins owing to lower cost structures caused by rivalry in their markets).

The effects of concentration and the cost shifting hydraulic are felt by the Medicare program as well as by the private market. As a general matter, market dominance protected by significant barriers to entry tends to result in less innovation. In health care markets this suggests that the spur to undertake cost savings through the arduous process of changing long standing medical practices will be attenuated. Second, there is some evidence that market concentration produces lower quality, as measured by indices of mortality and outcomes. ${ }^{78}$ Such effects obviously redound to harm Medicare beneficiaries and private pay patients alike. Third, disparities in profit margins, if sufficient may reduce participation by providers, thereby undermining access for beneficiaries. Likewise, low margins for services specific to the Medicare population will result in less investment by providers in those services.

This section has demonstrated the close interconnection between private and public markets. Two salient policy prescriptions follow from this analysis. In regulating ACOs CMS should abandon its historic agnosticism with regard to cost shifting. Beyond carefully evaluating data gathered under the MSSP, it should insist that, as a condition of renewal after the expiration of their three year contracts, ACOs document pricing patterns in the private sector to determine whether significant cost-shifting has occurred and whether purported cost savings in the program were realized. The second implication for policy analysis, discussed in the next section, is that significant interagency cooperation between CMS and the antitrust agencies is needed to curb the anticompetitive effects that providers with dominant market power may wreak on both private markets and the Medicare program.

\section{Antitrust, Competition Policy and ACOs}

Concerns about the competiveness of provider markets have shadowed the MSSP implementation process. Policy experts, trade associations and academics have questioned whether local hospital and physician markets will be conducive to achieving the program's goals. $^{79}$ Three distinct issues must be considered. First, one must question whether ACOs can accomplish the MSSP's ambitious "triple aim" in the absence of vigorously competitive provider markets that will permit intra-network rivalry to flourish. Second, concerns have been raised as to whether the MSSP itself will stimulate additional concentration of provider markets and whether antitrust enforcement will be able to curb anticompetitive mergers and joint ventures. Finally, regulators will need to strike a balance between supervising quality and competitive conditions on the one hand, and encouraging entry by multiple networks in each market on the other.

Provider Concentration and Bargaining Leverage

77 MedPAC Report, supra note xx.

${ }_{78}^{78}$ See infra note $\mathrm{xx}$ and accompanying text.

79 See supra notes $\mathrm{xx}-\mathrm{xx}$ and accompanying text. 
Provider market power poses the biggest obstacle to the success of the ACO strategy. As a general matter, it is clear that over the last fifteen years providers have generally gained the upper hand in bargaining with payers. ${ }^{80} \mathrm{~A}$ large body of literature documents the existence, scope, and effects of market concentration. Meta-analysis by Vogt and Town demonstrates a strong correlation between hospital market concentration and escalating costs of health insurance: hospital consolidation in the 1990s raised overall inpatient prices by at least 5\%, and by $40 \%$ or more when merging hospitals were located close to one another. ${ }^{81}$ An important study undertaken by the Massachusetts Attorney General documents the effects of provider leverage on health care costs and insurance premiums, ${ }^{82}$ notably finding prices for health services are uncorrelated with quality, complexity, proportion of government patients, or academic status but instead are positively correlated with provider market power. ${ }^{83}$ Another report, drawing on site visits by the Center for Studying Health System Change to six California markets in 2008, found that provider leverage has had a "major impact on California premium trends." 84 Interviews in these markets revealed that the bargaining power of hospitals has been enhanced by extensive horizontal consolidation. In many markets around the country, hospitals have been able to establish themselves as "must have" hospitals --meaning health plans must include them in their networks to offer insurance products attractive to employers and consumers - by means of advertising, locational advantages, or other means that establish a "reputation for perceived quality — not to be confused with measured clinical quality." Finally, anecdotal evidence suggests that large multispecialty group practices and independent practice associations also exercise market power by virtue of a lack of price competition for their services. ${ }^{85}$

Other, subtler results have also flowed from the wave of consolidations and the marginalization of managed care. An important effect of increasing consolidation in hospital markets, generally ignored by antitrust analysis, is the effect of "cross-market" mergers, i.e. those occurring between hospitals in distinct geographic markets. Recent economic analysis has demonstrated that anticompetitive effects can occur where large hospital systems enhance their bargaining leverage vis a vis payers by threatening to create gaps or "holes" in payers' coverage in a geographic region. ${ }^{86}$ Second, besides price increases owing to enhanced bargaining power, growth in hospital costs appear to have been driven by strategic decisions that take advantage of market imperfections and the absence of effective monitoring by payers. By some accounts, the

${ }^{80}$ See Ginsburg Testimony, supra note xx, at 1-2 (summarizing site visits conducted by Center for Study of Health Systems Change and empirical studies of effects of increased provider concentration and finding a shift in the "balance of negotiating power...in favor of providers, particularly hospitals.").

${ }^{81}$ Robert Vogt \& Robert Town, How Has Hospital Consolidation Affected the Price and Quality of Hospital Care?, in THE SYNTHESIS PROJECT 2006 (Robert Wood Johnson Foundation Research Synthesis Report No. 9), available at http://www.rwjf.org/files/research/no9researchreport.pdf.

82 MassachusetTs AtTorney General, EXAmination of HEAlth CARE COST TRENDS AND Cost DRIVERS PURSUANT TO G.L. C. 118G, $\S 61 / 2$ (B) (2010), available at

http://www.mass.gov/ago/docs/healthcare/final-report-w-cover-appendices-glossary.pdf [hereinafter Health Care Cost Trends].

${ }^{83}$ Id. at 16-33.

${ }^{84}$ Robert Berenson et al., Unchecked Provider Clout in California Foreshadows Challenges to Health Reform, 29 HeALTH AFF. 699, 704 (2010). See also Ginsburg Testimony, supra note xx.

${ }^{85}$ See e.g., Ginsburg, supra note 84.

${ }^{86}$ Greg S. Vistnes, Cross-Market Hospital Mergers: A Holistic Approach available at SSRN. See also, Berenson, supra note 84 at 702 (noting that all-or-nothing bargaining increases leverage of regional hospital systems in California). 
"medical arms race" has resurfaced. ${ }^{87}$ That is, hospitals have undertaken significant expansions in high-margin services and have accelerated technology acquisitions, a phenomenon attributable in part to providers' capacity to induce demand. In addition, specialty physicians have proved unwilling to join multi-specialty practices, preferring to consolidate into single specialty practices. $^{88}$ The latter organizational form, which allows specialty physicians to reap the financial benefits of their bargaining leverage, also denies patients the clinical and cost-saving advantages associated with integrated practice arrangements.

The foregoing analysis, exposing the problem of extant provider market power, spells trouble for the ACO strategy. Hospitals and dominant physician specialty groups have been able to command substantial increases in reimbursement from private health insurers and effectively insulate themselves from pressures to accept change in payment or practice arrangements. Providers enjoying market power or "must have" status will be reluctant to cede control or equitably share revenues with other providers or substantially alter the way they practice medicine. While dominant providers may feel compelled to form ACOs out of concern that CMS may ultimately condition Medicare payments to strongly favor such organizations, they are likely to seek arrangements that entrench and perhaps expand their market power vis $a$ vis private insurers. A closely related concern is that monolithic ACOs dominant in multiple provider services will thwart the objective of ensuring multiple ACOs or other rivalrous networks in each market so as to promote continuing incentives to improve quality and lower costs over time. ${ }^{89}$ These concerns led HHS to enlist the support of the federal antitrust enforcement agencies to monitor the effects of additional provider consolidation stimulated by the MSSP.

\section{The FTC/ Department of Justice Statement of Enforcement Policy}

In conjunction with the issuance by CMS of the final MSSP regulations, the Department of Justice and Federal Trade Commission issued a final joint "Statement of Antitrust Enforcement Policy Regarding Accountable Care Organizations Participating in the Medicare Shared Savings Program." 90 The FTC/DOJ Statement, which made some significant changes from an earlier Proposed Statement, outlines the general enforcement policies the agencies will apply in analyzing the effect of CMS-approved ACOs on private insurance markets. Importantly, the antitrust agencies recognized the need to steer a delicate course between encouraging market entry and deterring agreements that impeded competition. Accordingly, the Final Statement attempts to strike a balance between (1) clarifying antitrust standards and review procedures applicable to participants in the private insurance market so as not to deter procompetitive cooperation and consolidation among providers and (2) exercising effective oversight of consolidations spurred by the MSSP that may damage competition in private markets.

The Final Statement is noteworthy for several policies designed to encourage ACO development and remove some uncertainties surrounding the application of antitrust law. First, it

\footnotetext{
87 See Robert A. Berenson et al., Hospital-Physician Relations: Cooperation, Competition, or Separation?, 26 HEALTH AFF. w31 (2007), available at http://content.healthaffairs.org/content/26/1/w31.full.pdf.

${ }^{88}$ Lawton Burns \& Mark V. Pauly, Integrated Delivery Networks: A Detour on the Road to Integrated Health?, 21 HeALTH AFF. 128 (2002).

${ }^{89}$ Final Rule, supra note $\mathrm{xx}$ at 67,841 (noting that CMS has stated that its objective is to have at least two ACOs in every market).

${ }^{90}$ Final Statement, supra note $\mathrm{xx}$.
} 
announces that CMS's eligibility criteria -- including a management structure that comprises clinical and administrative processes and processes to promote evidence-based medicine and patient engagement -- are broadly consistent with the agencies' prior statements regarding clinical integration. ${ }^{91}$ Through an extensive series of advisory opinions, ${ }^{92}$ policy statements ${ }^{93}$ and speeches, ${ }^{94}$ the FTC has articulated detailed criteria to identify physician networks that have undertaken sufficient coordination of clinical and organizational arrangements so as to make the physicians' efforts truly interdependent and hence not subject to summary condemnation as price fixing arrangements. The Final Statement also indicated that joint negotiations with private payers will be deemed reasonably necessary to an ACO's purpose of improving health care, and ACOs utilizing the same structure and processes used in the shared savings program to serve privately insured patients will accordingly be afforded rule of reason treatment. ${ }^{95}$ Together these statements effectively remove the possibility that an ACO certified by CMS will be regarded as price fixing and subject to strict, per se scrutiny. Finally the agencies also set parameters for market power and incorporate a new metric for assessing market power in ACO networks. The Final statement announces a "safety zone" for ACOs whose independent participants provide a "common service" and have a combined share of 30 percent or less of each such common service in each participant's primary service area. ${ }^{96}$ ACOs falling within the safety zone will be presumed to be "highly unlikely to raise significant competitive concerns." 97

These pronouncements constitute a modest relaxation of antitrust standards previously announced by the agencies. The standard for clinical integration applied by the FTC advisory opinions involves an examination of various indicia testing the degree of interdependence and cooperation among physician participants. ${ }^{98}$ As a general matter, the agency has sought to avoid

91 Final Statement, supra note $\mathrm{xx}$ at 67,027.

92 See e.g., Letter from Markus H. Meier, Assistant Director, Bureau of Competition, Federal Trade Commission, to Christi J. Braun, Attorney, Ober, Kaler, Grimes \& Shriver (Apr. 13, 2009), available at www.ftc.gov/os/closings/staff/090413tristateaoletter.pdf.

93 U.S. DEP'T OF JUSTICE AND FED. TRADE COMM'N, STATEMENTS OF ANTITRUST ENFORCEMENT POLICY IN HEALTH CARE (1996), available at http://www.justice.gov/atr/public/guidelines/0000.pdf.

94 See e.g., Thomas B. Leary, Remarks at the Saint Louis University Health Law Symposium (Apr. 12 , 2002), available at http://www.ftc.gov/speeches/leary/eicreview.pdf.

95 Final Policy Statement, supra note xx at 67,027.

96 Id. at 67,028 .

97 Id.

98 Summarizing the detailed analysis contained in four FTC advisory opinions assessing meaningful "clinical integration", Burke and Rosenbaum identify the following criteria: "systems to establish goals relating to quality and appropriate utilization of services;" regular evaluation of "both individual participants' and a network's aggregate performance with respect to those goals;" control over practice, as evidenced by the ability to "modify individual participants' actual practices where necessary based on those evaluations;" development of practice standards and protocols "to govern treatment and utilization of services;" use of information systems to gather aggregate and individual data on cost and quality; a dimension of financial risk in the sense of a "significant investment of capital to purchase such systems;" the investment of human resources in collective quality improvement; the upward reporting within the provider arrangement of "detailed reports on the cost and quality of services provided, and on the network's success in meeting its goals;" and a medical director and staff capable of conducting clinical quality improvement and performance reporting activities as well as rate negotiations. 
being overly prescriptive in its approach to clinical integration. Instead, its letters provided lengthy analyses of the features of each proposal, pointing to factors that tended to create a "high degree of interdependence and cooperation among physicians to control cost and ensure quality." 99 The letters also address a second question critical to ancillary restraint analysis: Is collective price negotiation reasonably necessary to accomplish the goals of the clinically integrated network? In the letters providing a favorable response, the FTC has relied upon evidence that an agreement on price promoted physician cooperation with standards and ensured network stability. ${ }^{100}$ It should be noted however that although the FTC has been broadly supportive of efforts to form networks relying on clinical integration, some within the agency hold the view that financial integration offers a more reliable incentive to produce efficiencies necessary to justify enhanced opportunities to exercise market power. ${ }^{101}$

In a notable concession aimed at reducing uncertainty and encouraging ACO development, the antitrust agencies have elected to defer to CMS on the issue of clinical integration. The Final Statement provides that "organizations meeting the CMS criteria for approval as an ACO are reasonably likely to be bona fide arrangements intended to improve the quality, and reduce the costs, of providing medical and other health care services through their participants' joint efforts." 102 The standards that will be applied by CMS to determine eligibility to participate in the MSSP are less specific, but broadly congruent with the standards identified by the FTC advisory opinions. ${ }^{103}$ Although some commenters have criticized the agencies for ceding their responsibility for monitoring competition in private markets to CMS, ${ }^{104}$ in this instance, deference appears entirely appropriate. The Final Statement's approach to clinical integration is an acknowledgement of the uncertainty inherent in a multi-factor, case-by-case evaluation of the

Taylor Burke \& Sara Rosenbaum, Accountable Care Organizations: Implications for Antitrust Policy, 19 Health L. Rep. (BNA) (2010).

99 Letter from Markus H. Meier, supra note 92 at 4 (quoting Health Policy Statements).

${ }^{100}$ Id. See also Letter from Jeffrey W. Brennan, Assistant Director, Health Care Services \& Products, Federal Trade Commission, to John J. Miles, Attorney, Ober, Kaler, Grimes \& Shriver (Feb. 19, 2002), available at http://www.ftc.gov/bc/adops/medsouth.shtm. But cf. Letter from Markus H. Meier, Assistant Director, Bureau of Competition, Federal Trade Commission, to Christi J. Braun and John J. Miles, Attorneys, Ober, Kaler, Grimes \& Shriver (Sept. 17, 2007), available at http://www.ftc.gov/bc/adops/gripa.pdf (stating mere claims of enhanced efficiencies insufficient to justify collective price setting); Letter from David R. Pender, Acting Assistant Director, Bureau of Competition, Federal Trade Commission, to Clifton E. Johnson and William H. Thompson, Attorneys, Hall, Render, Killian, Heath \& Lyman (Mar. 28, 2006), available at http://www.ftc.gov/os/2006/03/SuburbanHealthOrganizationStaffAdvisoryOpinion03282006.pdf.

101 J. Thomas Rosch, Remarks before the ABA Section of Antitrust Law Fall Forum (Nov. 17, 2011), available at $\mathrm{http}: / / \mathrm{www}$.ftc.gov/speeches/rosch/111117fallforumspeech.pdf (sharply questioning the Commission's solicitude toward clinical integration arrangements).

102 Final Policy Statement, supra note xx at 67,028.

103 Burke \& Rosenbaum, supra note 98 at 14 (finding a "high degree of concordance" between the FTC and CMS standards but acknowledge that "the degree of concordance would be even more so in ACO models that employ both clinical integration and financing arrangements that rely on population-based capitation and use of a salary-plus-performance-bonus payment system.”).

${ }^{104}$ Douglas Rosenthal et al., Affordable Care Act Signals New Direction for Antitrust Enforcement in Healthcare, 100 Antitrust \& Trade Reg. Rep. (BNA) 738 (2011) (noting antitrust agencies' position marks "a significant shift away from [their] traditional role in the health care sector and a partial surrendering of antitrust oversight"). 
clinical integration and a pragmatic effort to cooperate with CMS to encourage entry into the ACO market. At the same time, the agencies' deference to CMS regulatory standards marks a striking departure from their customary practice of evaluating competitive issues based on the specific conditions obtaining in individual circumstances and a general aversion to administrative regulation of markets.

Other aspects of the Final Statement are more controversial. For ACOs that meet CMS eligibility criteria, the antitrust agencies have established several important changes in their procedures and standards for review of possible antitrust problems. Notably these provisions are designed to give some reassurance to entities forming ACOs that their formation and operation will not be subject to federal antitrust challenge based on the ACOs' effects in the private market. Approval, however, will not be a precondition for participation in the MSSP. As we will see, this change constitutes an important misstep that may severely undermine effective policing of dominant providers.

To further advance the goals of reducing uncertainty and encouraging ACO formation, the Final Statement establishes a "safety zone" for ACOs that combine independent providers by means other than merger. ACOs meeting the antitrust agencies' standards are "highly unlikely to raise significant competitive concerns." To qualify, ACOs must satisfy the following two requirements to fall within the Safety Zone: (1) "independent ACO participants ... that provide the same services ... must have a combined share of 30 percent or less of each common service in each participant's PSA, wherever two or more ACO participants provide that service to patients from that PSA"; and (2) "Any hospital or ambulatory surgery center ... participating in an ACO must be non-exclusive to the ACO ... regardless of its PSA share." 105 The PSA referred to above is a measure - and one not recognized in antitrust precedents - that will serve as a proxy for calculating combined market share of independent ACO participants. The antitrust agencies here opted for pragmatism over economic accuracy: the PSA standard as a to enable ACOs to calculate market power for safety zone eligibility using a convenient, administrable standard. ${ }^{106}$ The quantitative aspects of the standard are roughly equivalent to standards contained in the antitrust agencies' Health Policy Statements though in some respects it is more lenient. ${ }^{107}$ Moreover, ACOs comprised of dominant providers are subject to some restrictions, ${ }^{108}$ but are not precluded from qualifying for safety zone treatment. Significantly, enforcement for hospital dominated ACO would not be materially different than the environment facing

105 Final Policy Statement, supra note 90 at 67,029.

106 As defined in the Final Policy Statement, a PSA is the lowest number of postal zip codes from which the provider obtains at least 75 percent of its patients. Physician services are based on Medicare Specialty Codes as defined by CMS, and shares are calculated based on total Medicare allowed charges for claims billed. Inpatient services are based on Medical Diagnostic Categories and calculated based on patient discharge data; for outpatient services provided by hospitals or ambulatory surgery centers, shares are based on Medicare fee-for-service payment data for the common services categories. Final Policy Statement, supra note 90 at 67,031.

107 The 1996 FTC/DOJ Policy Statements on Healthcare provide set the safety zone for physician networks at 20 percent for exclusive networks, and 30 percent for non-exclusive networks. Dep't of Justice \& FTC, Health Care Policy Statements, Statement 8, supra note xx. ACOs may qualify for the safety zone with dominant providers with market shares --- is this sentence complete?

108 ACOs may contain a participant with greater than 50\% share of a service in its PSA if it is nonexclusive and no other ACO participant provides the same service in that PSA. 
physician-only ACOs; arguably this lowers the standard applied under the agencies Policy Statements which subjected multi-provider networks to more rigorous scrutiny than physicianonly networks. ${ }^{109}$

An overall appraisal of the Final Statement reveals, at most, a modest relaxation of antitrust standards for ACOs. Some aspects of prior safety zones are lessened: ACOs lacking financial integration may qualify as presumptively legal under the safety zone whereas a full rule of reason analysis was required under the Policy Statement. Further, ACO with exclusive networks combining providers up to 30 market share (rather than 20 percent), ACOs with a single provider with more than 50 percent of the services in one area, and multi-provider networks that include hospitals all may enjoy safety zone treatment. ${ }^{110}$ However these changes are not major departures from the earlier guidelines promulgated by the agencies, and may, in fact, be more stringent than the enforcement policies actually practiced by the FTC and Department of Justice. ${ }^{111}$ Of greater concern, as discussed in the next section of this article, are the measures not undertaken to expand and improve antitrust oversight of provider consolidation resulting from the formation of ACOs.

\section{Antitrust Law's Achilles Heel: Dealing with Extant Market Power}

A common misapprehension among legislators and policymakers is that antitrust law provides a reliable counterforce to monopoly. With respect to extant monopolies, legally acquired, the opposite is true: antitrust law tolerates the exercise of market power (which includes charging higher prices, reducing output, and/or lowering quality) and generally intervenes only where monopolists wrongfully exercise that power to exclude or harm rivals. ${ }^{112}$ Dominant hospital systems and provider groups face little danger that they will be broken into smaller units. Moreover they are free to insist on monopoly levels of reimbursement and the extensive literature on hospital-payor bargaining confirms that dominant providers commonly exercise their positional leverage vis a vis private payers. ${ }^{113}$

Nothing in the CMS Final Rule, the antitrust agencies' Final Statement, or federal antitrust enforcement policies suggests that the regulation of ACOs will lessen extant provider concentration. For example, despite the recent wave of physician acquisitions by hospitals and mergers of competing providers, the agencies did not take steps to incorporate retrospective reviews of mergers into their evaluation of ACO applicants under the MSSP. ${ }^{114}$ Indeed, ACOs with dominant providers will qualify for safety zone treatment if they are nonexclusive. ${ }^{115}$

\footnotetext{
109 Kasper, supra note $\mathrm{xx}$ at 231.

110 Final Policy Statement, supra note $\mathrm{xx}$ at 67,029. See Kasper, supra note $\mathrm{xx}$ at 231-2(comparing safety zone treatment and other provisions of the 1996 Policy Statements and the Final Policy Statement).

111 See Thomas L. Greaney, Thirty Years of Solicitude: Antitrust Law and Physician Cartels, 7 Hous. J. HEALTH L. \& POL'Y 189 (2007) (describing lax antitrust enforcement for physician networks).

112 See Verizon Communications Inc. v. Trinko, 540 U.S. 398 (2004) (stressing need to confine reach of Section 2 of the Sherman Act in order to preserve incentives to innovate, avoid risks of false positives, and preserve monopolists' "right" to choose trading partners).

113 See supra, notes $\mathrm{xx} \& \mathrm{xx}$ and accompanying text.

114 See infra, notes $\mathrm{xx}$ and $\mathrm{xx}$ and accompanying text.

115 See supra, note $\mathrm{xx}$ and accompanying text.
} 
Hence it is clear that many ACOs will be comprised of providers with market power. To the extent that ACOs combine providers with some degree of market power, the MSSP may actually enhance the bargaining power of those providers and also enable the ACO to leverage that power to benefit other provider segments that did not have bargaining power prior to joining the ACO.

Despite its incapacity to de-concentrate markets, antitrust law does impose some restrictions on the exercise of market power by dominant firms. Firms that use their dominant position to exclude rivals, raise their costs, or otherwise hinder the competitive process may be subject to treble damages or injunctions under the Sherman Act. Several recent cases illustrate the ability of dominant providers to insist on exclusionary contracts (sometimes with dominant insurers) that impair the ability of rival hospitals to compete. For example in United States $v$. United Regional Health Care System, ${ }^{116}$ a case recently settled by a consent decree, the Department of Justice alleged that the defendant, a dominant, "must-have" hospital ${ }^{117}$ entered into contracts with commercial health insurance companies, requiring the insurance companies had to pay a "substantial pricing penalty," ranging from $13 \%$ to $27 \%$, if the insurers also contracted with competing providers. Though rationalized by defendants as "discount" pricing, the government claimed they were of such magnitude as to make it commercially unreasonable for an insurance company to enter into a contract with competing hospitals, unless the competing hospital would agree to prices below United Regional's marginal cost. The government claimed that by foreclosing rivals from the most profitable health insurance contracts, defendant was able to entrench its market dominance. ${ }^{118}$

In another case involving allegations of exclusionary contracting by a dominant hospital, West Penn Allegheny Health System, ${ }^{119}$ the second-largest hospital system in Pittsburgh, alleged that the dominant hospital system in the market, University of Pittsburgh Medical Center, conspired with Highmark Inc., the market's dominant insurer in a scheme designed to protect both defendants from competition in their respective markets. West Penn Allegheny claimed that UPMC had agreed to refuse to enter into competitive provider contracts with Highmark's rivals and take other steps advantageous to Highmark in return for Highmark's agreement to pay to UPMC "supracompetitive reimbursement rates" made possible by increasing its insurance premiums. ${ }^{120}$ The Third Circuit found the alleged conduct, amounting to a conspiracy between UPMC

\footnotetext{
116 United States v. United Regional Health Care System, No. 7:11-cv-00030-O (N.D. Tex. Filed Feb. 11, 2011), available at $\mathrm{http}: / / \mathrm{www} . j u s t i c e . g o v / a t r / c a s e s / f 276000 / 276027 . p d f$.

117 The government's complaint alleged that United controlled approximately $90 \%$ of the market for inpatient services sold to commercial insurers market and $65 \%$ of the market for outpatient surgical services sold to commercial insurers. United States v. United Regional Health Care System, No. 7:11-cv00030-O, slip op. at 1 (N.D. Tex. Sept. 29, 2011), available at http://www.justice.gov/atr/cases/f276000/276027.pdf.

${ }_{118} I d$. at yy.

119 West Penn Allegheny Health System, Inc. v. UPMC, 627 F.3d 85 (3d Cir. 2010).

${ }^{120} \mathrm{Id}$. at 93.
} 
and Highmark to drive out West Penn out of the market, sufficiently anticompetitive to survive a motion to dismiss. ${ }^{121}$

Finally, Cascade Health Solutions v. PeaceHealth ${ }^{122}$ illustrates the exercise of pricing power by a dominant hospital. This case arose in a two hospital market: Cascade offered primary and secondary care services while PeaceHealth offered primary, secondary, and tertiary care services. The alleged anticompetitive conduct focused on PeaceHealth pricing strategy involved discounts on tertiary services to insurance companies that made PeaceHealth their exclusive provider for primary, secondary, and tertiary services. In addition, PeaceHealth also offered less favorable prices generally to insurance companies that contracted with Cascade as a preferred provider for primary or secondary care services. Plaintiff alleged defendant's "bundled" pricing operated to exclude it from the market in violation of the Sherman Act. Ultimately, the Ninth Circuit adopted a test that struck a middle ground between competing standards found in precedents, scholarship and a commission chartered to study antitrust doctrine. ${ }^{123}$ However much remains unresolved as to the appropriate measure of improper bundled pricing or the test to determine the likelihood of harm to consumers. ${ }^{124}$

These and other cases ${ }^{125}$ involving the interplay hospital and payor dominance yield several important lessons. Hospitals with market power may seek to entrench or extend their dominant position by a variety of contracting or pricing schemes. In some instances, dominant payers and dominant hospitals have reached understandings pursuant to which each will refrain from hard

${ }^{121} I d$. at yy. That, however, was not the end of the saga. A month after UPMC's petition for certiorari was dismissed Highmark and West Penn announced merger plans (with Highmark stating it would invest \$475 million in West Penn). Not surprisingly, West Penn dismissed its complaint against Highmark.

${ }^{122}$ Cascade Health Solutions v. PeaceHealth, 502 F.3d 895, (9th Cir. 2007).

123 Concluding that only discounts resulting in prices that are below an appropriate measure of the defendant's costs would be subject to antitrust challenge; the court adopted a discount attribution test recommended by the Antitrust Modernization Commission. Id. at 916. At the same time it rejected the argument that plaintiff must prove the likelihood that defendants could recoup lost profits from their pricing practices. See generally Jeffrey A. Jaekel, Lepage's, Cascade Health Solutions, And A Bundle Of Confusion: What Is A Discounter To Do?, 24 ANTITRUST 46 (2010).

124 Compare Mark S. Popofsky, Section 2, Safe Harbors, and the Rule of Reason, 15 GEO. MASON L. REV. 1265, 1290-94 (2008) (criticizing PeaceHealth for rejecting recoupment requirement) with Einer Elhauge, Tying, Bundled Discounts, and The Death of the Single Monopoly Profit Theory, 123 HARV. L. REV. 397, 461-75 (2009).

125 See e.g., United States v. Blue Cross Blue Shield of Michigan, No. 10-cv-14155-DPH-MKM (E.D. Mich. filed Oct. 18, 2010) (denying motion for summary judgment in case alleging dominant health insurer used anticompetitive "most favored nation" ("MFN") clauses in its contracts with hospital providers to foreclose competition in health insurance market while also increasing hospitals' reimbursement); Texas v. Memorial Hermann Healthcare Sys., No. 2009-04609 (Tex. Dist. Ct. filed Jan. 26, 2009) (settling antitrust claims that largest hospital system in Houston discouraged commercial insurers from contracting with rival hospitals by threats of termination or demands for large increases in reimbursement); Heartland Surgical Specialty Hospital v. Midwest Division, Inc., 527 F.Supp.2d 1257, (D. Kan. 2007) (denying summary judgment in case involving alleged conspiracy between combination of hospitals accounting for $74 \%$ of local market and insurers accounting for $90 \%$ of managed care contracts to prevent new specialty hospital from obtaining managed care contracts). 
bargaining with the other ${ }^{126}$ or will deal on unfavorable terms with the other's rivals. ${ }^{127}$ While antitrust litigation can challenge these tactics, such cases are fact-intensive, require extensive analysis, and in areas in which the law remains unsettled. For example, plaintiffs alleging anticompetitive bundling or tying face notoriously high evidentiary burdens and there is considerable dispute over the legal standard that is applicable. ${ }^{128}$ As a result, antitrust law is more paper tiger than bulwark against abuse when dealing with incumbent monopolies. The following section analyzes other avenues of redress against conduct by dominant providers in the context of regulating ACOs.

\section{Addressing Anticompetitive Conduct in ACOs: The Four "No-Nos," Mandatory Agency Review, and its Demise}

In drafting their Policy Statements and coordinating with CMS, the antitrust agencies were acutely aware of risk that extant market power would undermine the procompetitive benefits of the ACO strategy. However, a significant change from the framework set forth in CMS's Proposed Rule and the antitrust agencies' Proposed Statement severely undermined prospects for achieving some measure of control over potential anticompetitive conduct. Both the Proposed Statement and the Final Statement identify specific categories of conduct, which the Statements counsel may, under certain circumstances, raise competitive concerns and should be avoided. The most obvious warning is directed at garden-variety horizontal collusion. The Final Statement counsels that ACO participants should avoid improper exchanges of price or other competitively sensitive information among competing participants, which may facilitate collusion in the provision of services outside the ACO. ${ }^{129}$ The remaining four categories entail vertical arrangements that have the potential to foreclose competition by rival networks or raise entry barriers. These warnings, ${ }^{130}$ directed to ACOs with high PSA shares (or other indicia of market

${ }^{126}$ A Handshake That Made Healthcare History, Bos. GLOBE, (Dec. 28, 2008), http://www.boston.com/news/specials/healthcare_spotlight (reporting agreement between dominant insurer, Blue Cross Blue Shield of Massachusetts, and dominant hospital system Partners Health Care pursuant to which Blue Cross would give Partners higher levels of reimbursement, in exchange for Partners' promise that they would demand the same rate increases from everyone else.

127 See e.g., U.S. v. Blue Cross Blue Shield of Michigan, discussed supra note xx; West Penn Allegheny Health System, Inc. v. UPMC, discussed supra note xx; United States v. United Regional Health Care System, No. 7:11-cv-00030-O (N.D. Tex. filed Feb. 25, 2011), discussed supra note xx.

128 See Jaekel, supra note $\mathrm{xx}$.

129 Final Policy Statement, supra note xx at 67,029. The Final Statement distinguishes this warning from the others by removing it from the list of five kinds of conduct where it had been placed in the Proposed Statement. See Proposed Statement, supra note xx at 21,898.

130 Although appearing under the heading "Conduct to Avoid," the four items are later described in the Statement as "conduct that may raise anticompetitive concerns." Final Policy Statement, supra note xx at 67,030. It also acknowledges that each category of conduct "may be competitively neutral or even procompetitive, depending on the circumstances, including whether the ACO has market power." Id. The Statement goes on to tie the degree of risk to the amount of market power possessed by ACO participants. It illustrates this standard with the example of an ACO that requires its participants to contract exclusively through the ACO, stating that exclusivity designed to increase an ACO's efficiency "is generally less likely to raise competitive concerns the greater the number of competing ACOs or independent providers available to contract with private payers or to participate in competing ACOs or other analogous collaborations." Id. 
power), are designed to deter the exercise of market power that "may prevent private payers from obtaining lower prices and better quality services for their enrollees." 131

1. Discouraging private payers from directing or incentivizing patients to choose certain providers thorough contractual terms such as "anti-steering," "anti-tiering," "guaranteed inclusion," and "most favored nations" provisions.

2. Tying sales of the ACO's services to the private payer's purchase of other services from providers outside the ACO, and vice versa.

3. Contracting with ACO participants on an exclusive basis.

4. Restricting a private payer's ability to make available cost, quality, efficiency and performance information to aid enrollees in evaluating and selecting providers in the health plan if it is similar to that used in the shared savings program.

A very significant aspect of the antitrust agencies' Proposed Statement was the screening process that CMS and the agencies decided not to pursue. Backing away from the approach set forth in their Proposed Statement, the agencies and CMS eliminated a requirement for mandatory antitrust review as prerequisite to certification for participation in the MSSP. Mandatory review had initially been contemplated for all ACOs whose share for any common service that two or more independent ACO participants provided to patients in the same primary service area exceeded 50 percent. ${ }^{132}$ Thus it subjected those ACOs comprised of dominant providers to close antitrust scrutiny both as to their structural characteristics and conduct in the commercial market. The preapproval requirement held the promise of accomplishing two objectives. First, it could serve to discourage formation of ACOs aiming to press the structural boundaries set forth in the Statements. Further, as discussed below, the mandatory review process gave the antitrust agencies additional bargaining leverage in dealing with anticompetitive conduct of the kind described in the agencies' four antitrust warnings.

CMS also justified mandatory review as serving the interests of the MSSP program for Medicare beneficiaries, arguing it provided assurance that participating ACOs would not be later found to present competitive problems that could subject them to antitrust challenge that could prevent them from completing the term of their agreement. ${ }^{133}$ In addition, the agency legitimated mandatory review by drawing an explicit link between vigorous private market competition and the interests of the Medicare Program:

[Mandatory antitrust review] would maintain competition for the benefit of Medicare beneficiaries by reducing the potential for the creation of ACOs with market power. In this context market power refers to the ability of an ACO to reduce the quality of care furnished to Medicare beneficiaries and/or to raise prices or reduce the quality for commercial health plans and enrollees, thereby potentially increasing providers' incentives to provide care for private enrollees of higher-paying health plans rather than for Medicare beneficiaries.

...[C]ompetition in the marketplace benefits Medicare and the Shared Savings Program because it promotes quality of care for Medicare beneficiaries and

\footnotetext{
${ }^{131} I d$.

${ }^{132}$ Proposed Statement, supra note $\mathrm{xx}$ at 21,898.

133 Final Rule, supra note $\mathrm{xx}$ at $67,841$.
} 
protects beneficiary access to care. Furthermore, competition benefits the Shared Savings Program by allowing the opportunity for the formation of two or more ACOs in an area. Competition among ACOs can accelerate advancements in quality and efficiency. All of these benefits to Medicare patients would be reduced or eliminated if we were to allow ACOs to participate in the Shared Savings Program when their formation and participation would create market power. ${ }^{134}$

In its Final Rule however, CMS and the agencies withdrew the mandatory review requirement. Without fully crediting any particular objection, CMS noted a number of criticisms it had received. Some commenters claimed mandatory review conferred unreviewable authority on the antitrust agencies to disqualify entities from participating in the Medicare Shared Savings Program which is subject to the regulatory oversight of HHS alone. According to this line of argument the transfer of oversight violated a rarely-invoked administrative law principle, the subdelegation doctrine. ${ }^{135}$ Others objected that the process converted antitrust review into a regulatory process, imposed entry-inhibiting costs on ACOs, and unduly focused regulators' attention on market structure rather than conduct. ${ }^{136}$ On the other hand, some comments, primarily from third party payors, argued that the mandatory review policy should be strengthened, such as by setting the PSA market level requiring review at $40 \%$ or favoring ACOs without market power until the agency had enough experience to calibrate and refine the program. $^{137}$

Without acknowledging the merits of the subdelegation arguments or other concerns, CMS chose to abandon mandatory review, stating that it believed it could accomplish its announced objectives through a three-pronged, "less burdensome approach." "138 First, the antitrust agencies will make available an expedited voluntary program for reviewing antitrust problems raised by any ACO applicant. Second, CMS promised to provide the Antitrust Agencies aggregate claims data which will assist the Antitrust Agencies in calculating PSA shares for ACOs participating in the Shared Savings Program and will require newly formed ACOs to agree, as part of their application to participate in the MSSP to share their MSSP application with the Antitrust Agencies. ${ }^{139}$ Third, the antitrust agencies would "rely on existing enforcement processes for evaluating concerns... and filing antitrust complaints when appropriate. $" 140$ Perhaps acknowledging it had served some pretty weak tea, CMS opened the door for coordinating with the antitrust agencies scrutiny of competition issues in the future. The Final Rule states that CMS has requested that the Antitrust Agencies "conduct a study examining how ACOs participating in the Shared Savings Program have affected the quality and price of

\footnotetext{
${ }^{134}$ Final Rule, supra note 7 at $67,841$.

135 Richard D. Raskin, Ben J. Keith \& Brenna E. Jenny, Delegation Dilemma: Can HHS Required Medicare ACOs to Undergo Pre-Clearance by the Antitrust Agencies?, 20 HEALTH L. REP. 961 (2011).

${ }^{136}$ Final Rule, supra note xx at yy.

137 Id.

138 Final Rule, supra note 7 at 67,843 . The Final Rule did not acknowledge the validity of the subdelegation argument or address whether alternatives short of expressly delegating preapproval such as obtaining evaluative reports from the antitrust agencies was considered.

139 Final Rule, supra note 7 at $67,842$.

${ }^{140} I d$.
} 
health care in private markets," anticipating possible use of the study "to evaluate whether we should, in the future, expand our eligibility criteria so that we consider competition concerns more explicitly in the Shared Savings Program application review process.",141

\section{Roads Not Taken}

As discussed in the foregoing sections, the Final Rule did little to protect private markets from potentially harmful spillovers resulting from the development of ACOs under the MSSP. We have seen that antitrust enforcement provides no relief from the lawful exercise of extant market power. Further, claims of foreclosure of competition by tying, bundling, and exclusionary contracting involve some unsettled issues of law and require extensive factual investigation. It was therefore unrealistic to expect antitrust enforcement to provide a timely or dependable bulwark against the exercise of market power as ACO's form and establish themselves in local markets. Given the serious prospects of cost shifting and spillovers in private insurance markets, a prophylactic, regulatory approach would have been desirable. This section discusses some of the missed opportunities and remaining options for competition-improving regulation.

The most direct path would have been to impose ex ante requirements aimed at preventing anticompetitive behaviors. This appraisal could have occurred at the screening stage of MSSP applicants and applied where the review revealed marginally excessive concentration or problematic agreements among participants in an ACO. However, foregoing mandatory review severely undermined the antitrust agencies' leverage to insist on preconditions. Lacking the gatekeeping power that follows from requiring agency clearance, the FTC and Department of Justice were denied the opportunity to negotiate binding conditions of participation as is commonly done in consent decrees in merger cases. ${ }^{142}$ For example, CMS might have imposed various regulatory conditions for MSSP participation such as heightened transparency or prenotification in close cases that could have reduced risks of anticompetitive conduct or better positioned the antitrust agencies to undertake timely enforcement actions.

A further problem with the approach to provider dominance in the Final Rule and Final Statement is that the antitrust agencies' MSSP scrutiny focuses only collaborations of otherwise independent providers. Other than requiring nonexclusive contracting in some circumstances and the four warnings on conduct, the rule does not require any special review of ACOs formed by dominant providers or where dominance is the result of mergers rather than collaborative contracting. As one commenter pointed out, this places asymmetric administrative burdens on smaller ACOs seeking to enter into acceptable collaborative arrangements, and may perversely

${ }^{141}$ Final Rule, supra note $\mathrm{xx}$ at 67,843

142 See U.S. DePT. OF Justice, AnTitrust Division Policy Guide to Merger ReMEdies 12-16 (2011), available at http://www.justice.gov/atr/public/guidelines/272350.pdf (discussing a "panoply" of conduct remedies that may be used to preserve competition especially in vertical merger cases, including provisions requiring "firewalls," non-discrimination, mandatory licensing, transparency, nonexclusive contracting). 
encourage the independent providers to consolidate into a larger single entity (or in the case of physicians, to seek employment with hospitals). ${ }^{143}$ Indeed a policy that more closely scrutinizes mergers and favoring collaborations by smaller providers rather than mergers or employment relationships would have the pro-competitive virtue of leaving open the possibility that individual providers might at some point withdraw and form new networks or rivalrous ACOs.

Intermediate regulatory options were also available. Commenters on Proposed Rule suggested a number of steps that CMS might take to reduce the risks of anticompetitive harm from dominant provider ACOs. For example, several suggested ways to improve detection and analysis of competitive conditions such as collaborative data collection by CMS and the antitrust agencies, mandating public reporting on the cost and price of care, and close monitoring of provider pricing in commercial markets. ${ }^{144}$ Another means of promoting competitive bargaining would be to require monopoly hospitals, on request of buyers, to unbundle their competitive services in negotiations with employers or payers. As suggested in a path-breaking article by Professors Havighurst and Richman, requiring hospitals to separate offerings of monopolized services from the "cluster market" of competitively-supplied acute care services would preserve a competitive market for services that are not monopolized and would make more transparent the pricing in services dominated by a single provider. ${ }^{145}$ Payers could then bargain down the prices of those services having good substitutes and might be able to encourage pricing restraint or growth of competitive alternatives for the monopolized services. ${ }^{146}$ While antitrust litigation might be directed to achieving this result, ${ }^{147}$ other options would offer more immediate and comprehensive relief. For example, state health insurance exchanges or state regulators might require unbundling on a targeted or across the board basis and CMS pursuant to its review the performance of ACOs and their impact on commercial markets might impose similar requirements. ${ }^{148}$

Another issue amenable to increased regulatory oversight is exclusive contracting by ACO providers. Preventing exclusive arrangements by dominant providers is a crucial component of a pro-competitive ACO policy. ${ }^{149}$ Without it, many ACO would readily achieve de facto dominance by virtue of their preexisting market power of their key providers, something that has become commonplace in most markets. ${ }^{150}$ At the same time, exclusive contracting can be a vital pro-competitive ingredient where providers do not have market power, as it generally

${ }^{143}$ Letter from Harold D. Miller, Executive Director, Center for Healthcare Quality and Payment Reform, to Donald S. Clark, Secretary, Federal Trade Commission (May 31, 2011), available at http://www.ftc.gov/os/comments/aco-comments/00040-60100.pdf.

144 Final Rule, supra note xx at 67,948.

${ }^{145}$ Clark C. Havighurst \& Barak D. Richman, The Provider Monopoly Problem in Health Care, 89 Or. L. J. 847 (2011).

${ }^{146} I d$. at 867.

${ }^{147} I d$.

${ }^{148}$ See generally, Thomas L. Greaney, Testimony before the U.S. House of Representatives Committee on the Judiciary Subcommittee on Intellectual Property, Competition and the Internet (May 18, 2012) available at http://judiciary.house.gov/hearings/Hearings\%202012/Greaney\%2005182012.pdf.

149 See supra notes $\mathrm{xx}$ and accompanying text.

150 See supra notes $\mathrm{xx}$ and accompanying text. 
encourages long term investments of human and financial capital in the enterprise. The Final Rule conditions safety zone treatment on all any hospital or ambulatory surgery center being non-exclusive to the ACO. ${ }^{151}$ The rule of non-exclusivity also applies to rural hospitals or dominant providers for ACOs that seek to qualify under the rural and dominant provider exceptions. The test for nonexclusivity, drawn from the Agencies Health Care Policy Statements is that an ACO must be "non-exclusive in fact and not just in name," evidenced by a showing that providers actually individually participate in, or contract with, other networks or managed care plans; evidence of their willingness and incentive to do so; and evidence that they earn substantial revenue from other networks or through individual contracts with managed care plans. ${ }^{152}$ While these criteria may prove useful in a mature market, it is difficult to see how they can be applied ex ante in the ACO context. ${ }^{153}$ A more fruitful approach would be to establish by regulation preconditions for ACO approval that include clear commitments to participate in other networks with financial penalties, termination or nonrenewal for noncompliance.

On a more prescriptive path, several options are available. CMS could make more explicit that it is likely to deny renewal of authority for ACOs to participate in the MSSP where it finds evidence of spillovers in the form of price increases and cost shifting to the private sector resulting from market power. Perhaps the boldest move would have been to bar ACOs from participation in the MSSP that materially increased concentration or threatened to dominate their markets until entry by other ACOs occurred. ${ }^{154}$ Faced with delayed entry, providers might then realign to permit formation of multiple ACOs. Although this approach admittedly imposes short term losses to the Medicare program, it arguably prevents long term damage to local provider markets of considerably greater magnitude and duration. ${ }^{155}$ That is, vertical and horizontal

${ }^{151}$ Final Rule, supra note xx at 67,841. See also Final Policy Statement, supra note xx at 67,028 (citing standards set forth in the agencies' 1996 Health Policy Statements DOJ \& FTC Health Policy Statements supra note $\mathrm{xx}$ at $\mathrm{yy}$ ); $I d$. at 67,029 (to fall within a safety zone, ACOs with a dominant participant "cannot require a private payer to contract exclusively with the ACO or otherwise restrict a private payer's ability to contract or dealt with other ACOs or provider networks").

${ }^{152} I d$. at yy.

153 The FTC's experience applying this standard in evaluating physician networks suggests that exclusivity will be rarely found absent explicit agreements. See Greaney, Thirty Years of Solicitude, supra note 109 at 199.

${ }^{154}$ See Letter from Joseph M. Miller and Michael Spector, Counsel, America's Health Insurance Plans, to Federal Trade Commission and Department of Justice (May 31, 2011), available at http://www.ftc.gov/os/comments/aco-comments/00109-60306.pdf (parenthetical); Letter from Paul Markovich, Executive Vice President and Chief Operating Officer, Blue Shield of California, to Secretary, Federal Trade Commission (Nov. 4, 2010), available at http://www.ftc.gov/os/comments/acocomments/00029-60085.pdf (parenthetical) available at www.ftc.gov/os/comments/aco-comments, others. ${ }^{155}$ One commenter compared the estimated national cost savings that Medicare may realize from the MSSP, (approximately $\$ 510$ million over three years) to the total annual operating revenues for hospitals in one medium sized city ( $\$ 7$ billion). A small price increase caused by enhanced provider market power in countless markets around the country obviously would impose societal costs that dwarf losses to the Medicare program. Joe Miller, The Proposed Accountable Care Organization Guidance: A First Look 
consolidation in provider markets stimulated by the MSSP is likely to have adverse effects on price and quality in private markets without being susceptible to effective antitrust remedies. In

\section{Conclusion}

\section{Experience is the name everyone gives to their mistakes-Oscar Wilde ${ }^{156}$}

Much hangs on the success of the ACO experiment. The Affordable Care Act enjoys only a thin margin of popular support and has no other tool to spur rapid change in health care delivery. This article has identified an unfortunate administrative impasse that forestalled a cooperative regulatory approach to deal with the core issue of provider concentration. Why did a cross platform regulatory solution fail to emerge? A partial explanation described in this article is found in the divergence between the legal responsibilities and cultures of the agencies. CMS serves a classically regulatory function, overseeing quality, price and performance of providers using a variety of entry and command and control tools, and improvidently ignored the programs effects on private markets. The antitrust agencies rely largely on adjudicatory enforcement, supplemented by extensive use of advisory opinions and compliance guidelines. Antitrust enforcers are predisposed to abjure ex post regulation of the conduct of dominant market participants, preferring ex ante structural remedies. This mismatch of regulatory perspectives has placed private payors and the Medicare program at the mercy of dominant providers.

This article has sought to demonstrate that in order to effectively promote competition through ACOs and prevent harm to private markets it is necessary to police dominant providers, which in turn requires a degree of prescriptive regulation. Of course it is true that the MSSP is at the starting point of a learning curve. It is certainly possible that experience and data flowing from the initial round of ACO contracts will embolden regulators and Congress to undertake measures that attempt to deal with provider market power. Unfortunately for those who place their hopes on market solutions to health care costs, the next phase may result in more draconian regulation than would otherwise have been necessary.

Health Affairs Blog (April 14, 2011) http:/healthaffairs.org/blog/2011/04/14/the-proposed-accountablecare-organization-antitrust-guidance-a-first-look/.

156 OSCAR WILDE, LADY WINDERMERE's FAN (1892). 